\title{
The Role of AMPA Receptor in the Basolatral Amygdala on Aggression and Anxiety in Rats
}

\author{
Milad Ahmadi ${ }^{1}$, Ali Karimi-Godarzi ${ }^{*}$, Leila Alizadeh² \\ ${ }^{1}$ Department of Physiology, College of Veterinary Medicine, Karaj Branch, Islamic Azad University, Alborz, Iran. \\ ${ }^{2}$ Shefa Neuroscience Research Center, Khatam Alanbia Hospital, Tehran, Iran.
}

\section{A BSTRACT}

Introduction: According to the previous studies, neural pathway of the basolatral amygdala plays an important role in etiology and pathophysiology of depression, anxiety, and aggression. However, the exact role of the basolateral amygdala in anxiety needs to be elucidated. Using social interaction and elevated plus maze tests, the role of AMPA glutamate subreceptors in the basolatral amygdala on aggression and anxiety-like behaviors was investigated. Materials and Methods: After anesthesia, two cannulas were implanted in the basolatral amygdala in Wistar rats. After one week recovery, anxiety levels and different forms of aggression were analyzed by elevated plus maze and social interaction tests. Results: AMPA agonist was administered at $0.25,0.5$, and $1 \mathrm{mg} / \mathrm{kg}$ doses in the basolateral amygdala. Doses of 0.5 and $1 \mathrm{mg} / \mathrm{kg}$ were significantly increased time spent in the open arms and offensive sideway compared to sham group. In addition, activation of AMPA receptor at $1 \mathrm{mg} / \mathrm{kg}$ significantly decreased the stay and entrance percentage of open arm and offensive sideway. Conclusion: Our data indicate that AMPA receptors modulate the signaling in the basolateral amygdala and may affect anxiety and aggression.

\section{Key words:}

1. Receptors, AMPA

2. Amygdala

3. Anxiety

4. Aggression

* Corresponding Author: Ali karimi-Godarzi

E-mail: kajalclinic@gmail.com 


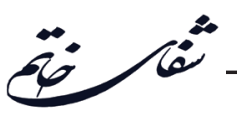

\title{
نقش گيرنده AMPA در هسته قاعدهاى -جانبى آميگدال بر روى يرخاشگرى و اضطراب در موشهاى صحرايى امينى
}

\author{
ميلاد احمدى'، على كريمى تودرزى ":، ليلا عليز اده \\ اكروه فيزيولوزى، دانشكده داميزشكى، واحد كرج، دانشَاه آزاد اسلامى، البرز، ايران. \\ كمركز تحقيقات علوم اعصاب شفا، بيمارستان خاتم الانبياء، تهران، ايران.
}

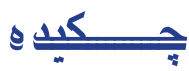

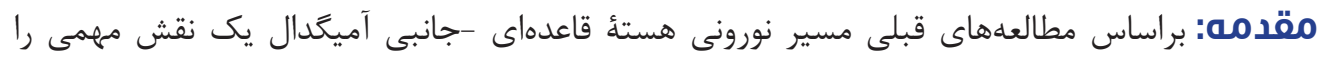

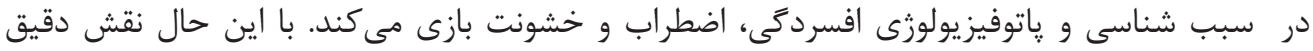

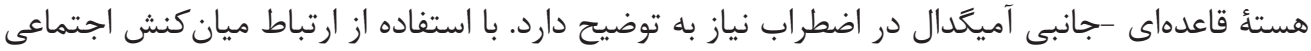

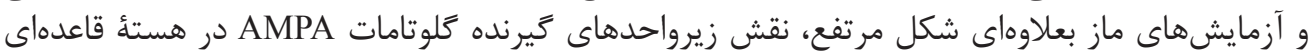

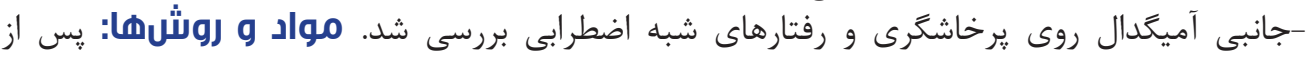

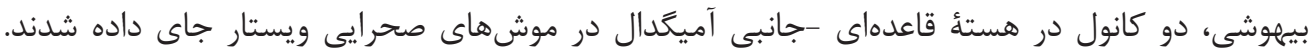

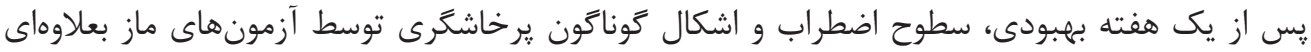

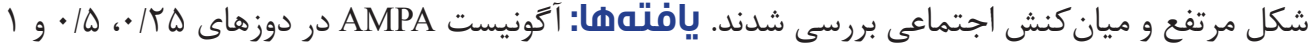

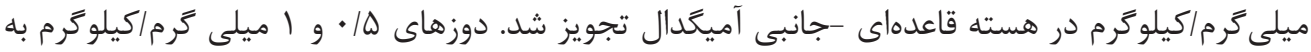

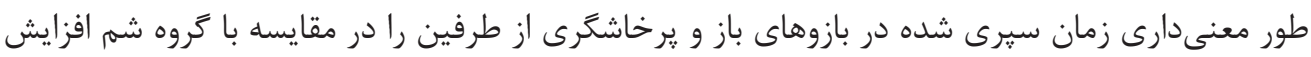

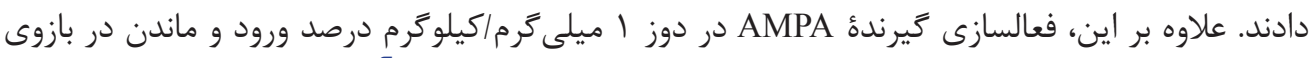

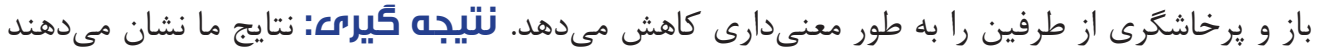

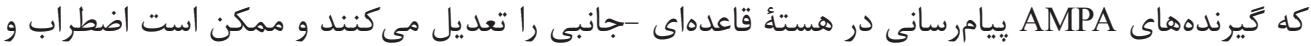
يرخاشكرى را تحت تأثير قرار دهند.

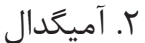

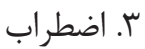

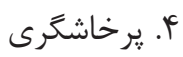

" نويسنده مسئول: على كريمى كودرزى آدرس الكترونيكى: kajalclinic@gmail.com 


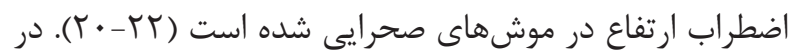

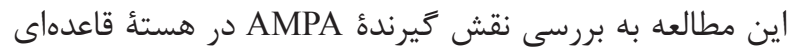

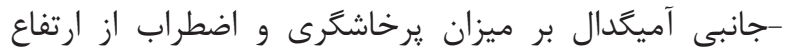

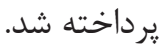

مواد و روشها - - ماد حيوانات

به منظور انجام تحقيق، از تعداد $9 q$ عدد موش صحرايى نر

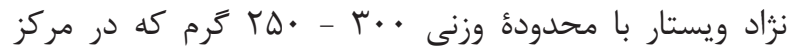

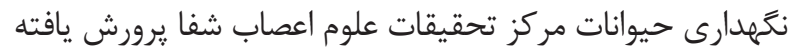

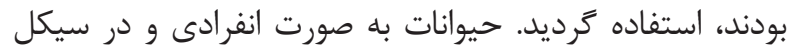

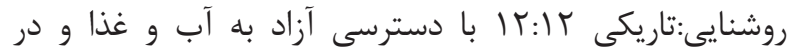
درجة حرارت

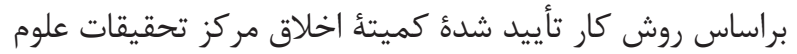

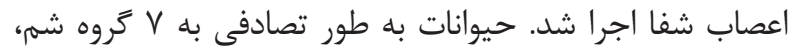
درمان با آكونيست گيرنده

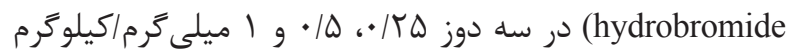

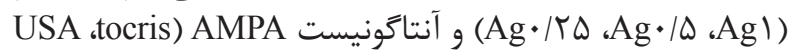

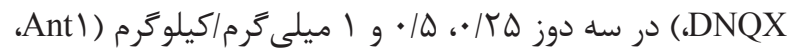

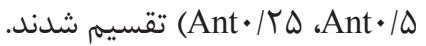
جر احى

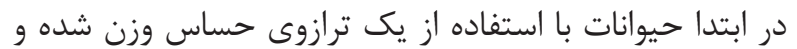

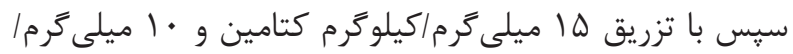

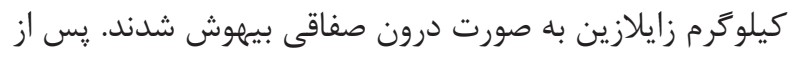

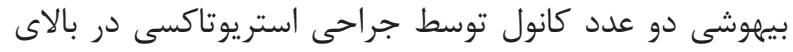

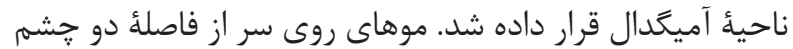

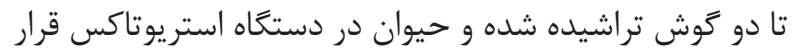

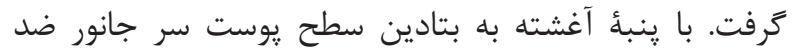

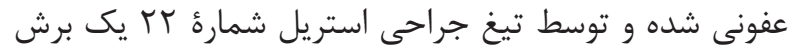

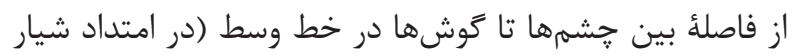

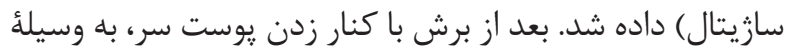

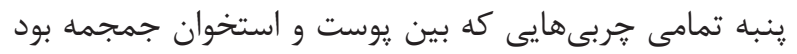

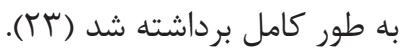

با استفاده از اطلس پاكسينوس و واتسون ويرايش ششم، ناحئ

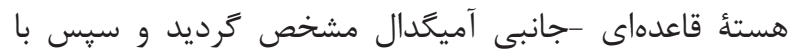

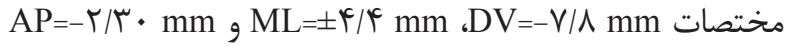

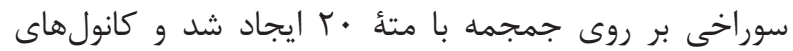

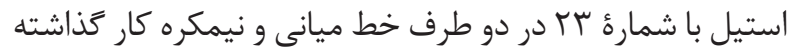

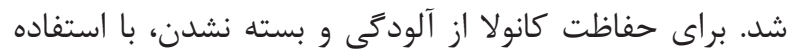

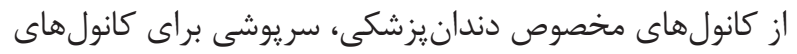

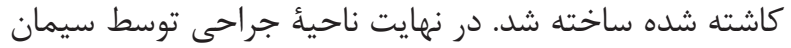

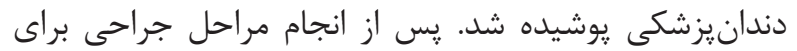

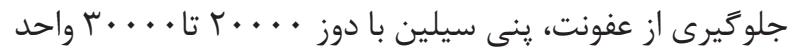

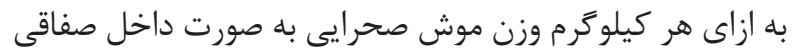

\section{${ }^{1}$ Manic}

2 Panic

${ }^{3}$ Nucleus Amygdala

${ }^{4}$ Glutamate

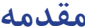

رفتار يرخاشگرى به عنوان خصوصيتهاى بسيارى از اختلال هاى

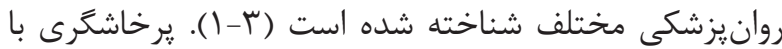

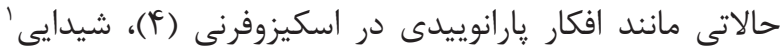

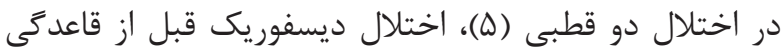

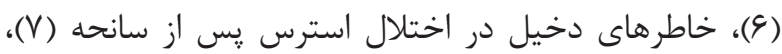

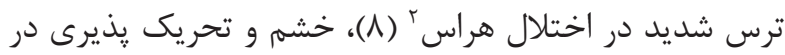

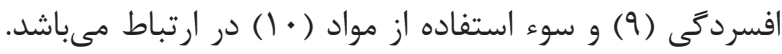

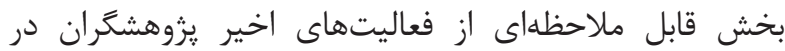

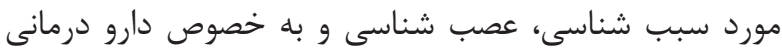

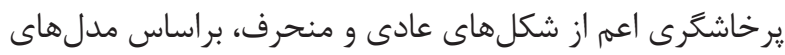

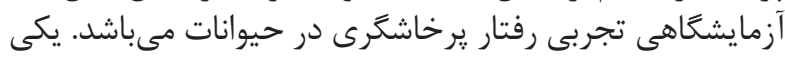

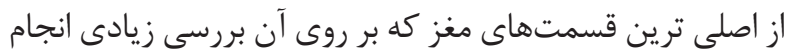

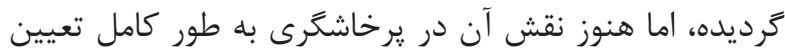

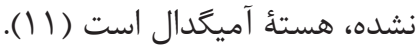

آميحدال يا هستهُ آميحدالَّ و يا در فارسى بادامه كه از وازئ يونانى amygdale

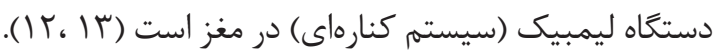

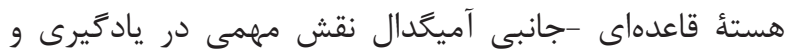

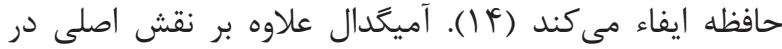

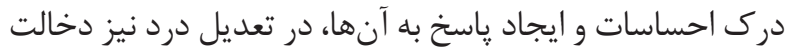

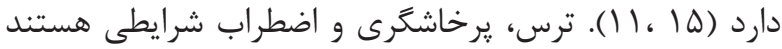

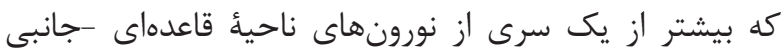

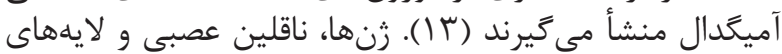

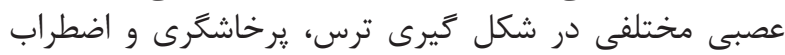

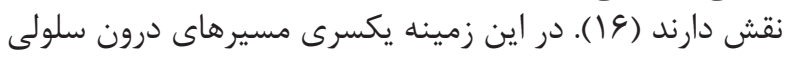

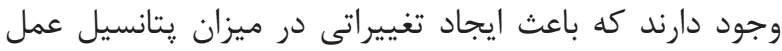

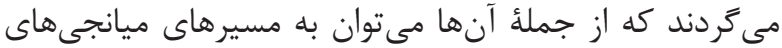

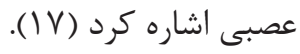

كلوتامات ^ يكى از اين ميانجى ها است كه باعث مى شود آبشارهاى

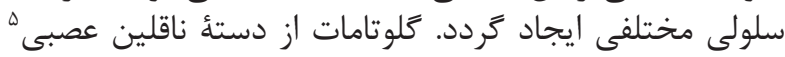

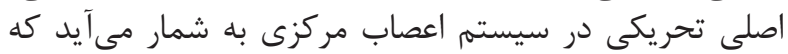

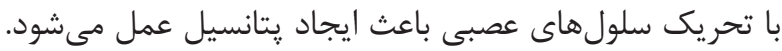

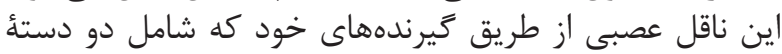

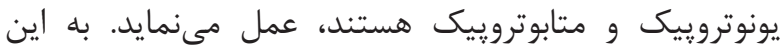

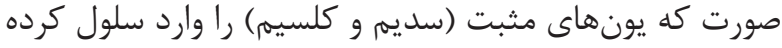

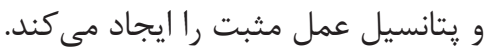

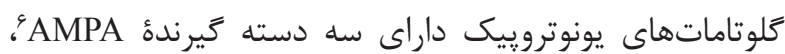

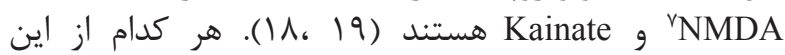
كيرندها در حضور كلوتامات فعال مىشيند

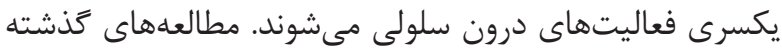

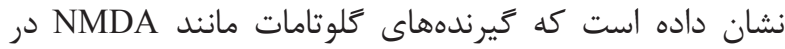

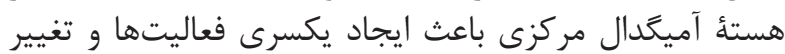

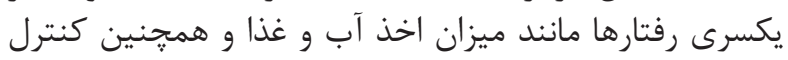

\footnotetext{
${ }^{5}$ Neurotransmitters

${ }^{6} 3$ - amino hydroxy-5-methyl-4-isoxazole propionic acid

${ }^{7} \mathrm{~N}$-methyl-D-aspartate
} 
آزمون رفتارى يرخاشگرى

بعد از آزمون اضطرابى، جهت انجام آزمون يرخاشكَرى هر يكى از

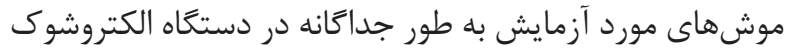

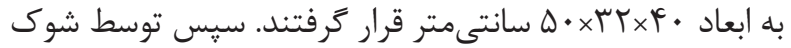

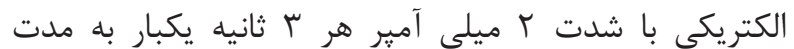

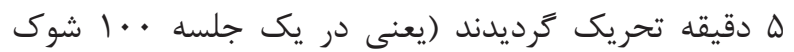

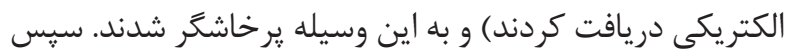

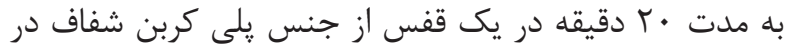

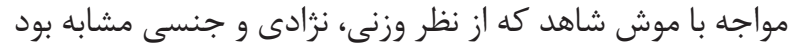

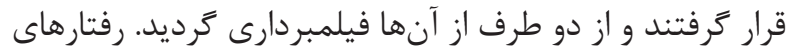

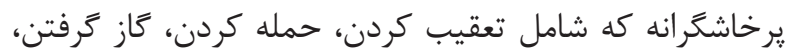

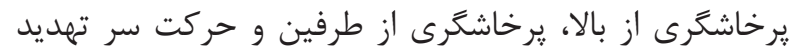

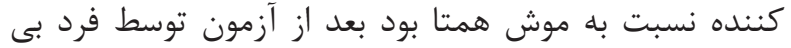

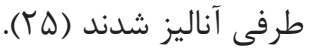

$$
\text { آناليز آمارى }
$$

تنها آن موشهايى كه كانول كذارى درستى شده بودند وارئ آردار

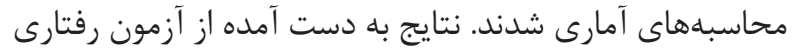

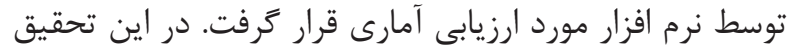

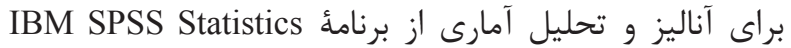

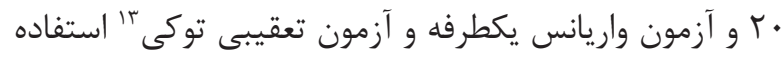

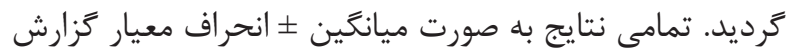

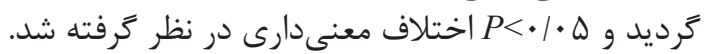

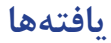

$$
\text { آزمون رفتارى اضطر ابى بأن }
$$

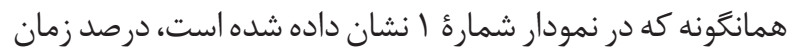

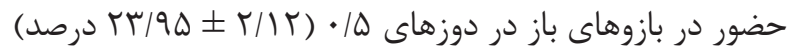

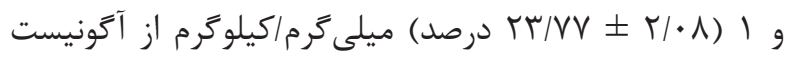

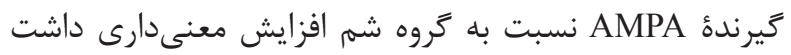

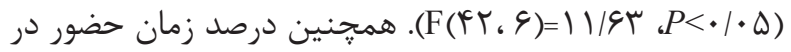

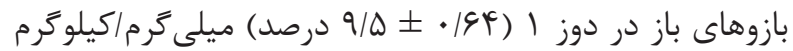
از أنتاگونيست كيرنده

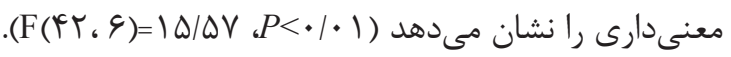

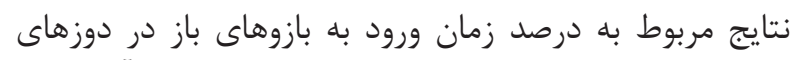

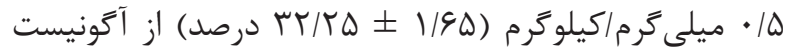

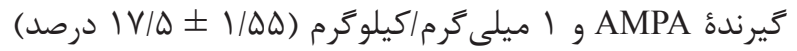
از آنتاكونيست گيرندة

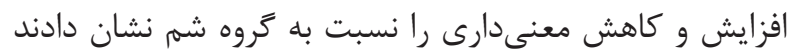

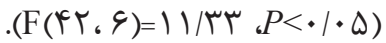

$$
\text { آزمون رفتارى يرخاشگرى }
$$

همانكَونه كه در نمودار ץ نشان داده شده است، تعداد حركت سر
تزريق شد. يُ إز اتمام جراحى همأ حيوانات يك هفته دورة بهبودى بعد از عمل را كَذراندند. تجري

$$
\text { تزريق دارو }
$$

بعد از كذشت يك هفته دورؤ بهبودى، در كروه شمه به ميزان

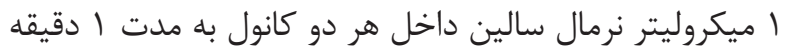

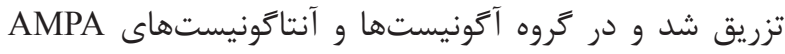

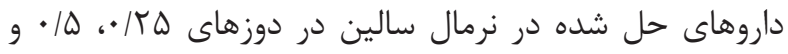
1 الميلى

$$
\text { -جانبى آميخدال تزريق شدمد }
$$

ه دقيقه بعد از تزريق داخل هستهٔ قاعدهاى -جانبى آميخدال

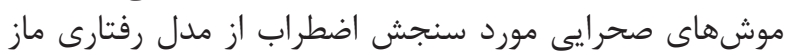

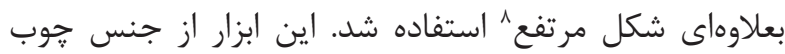

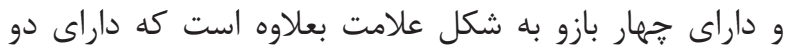

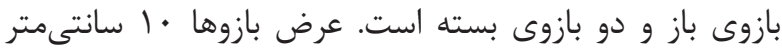

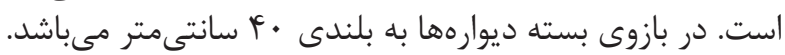

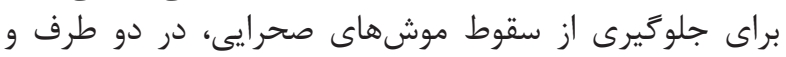

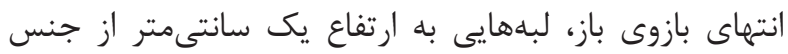

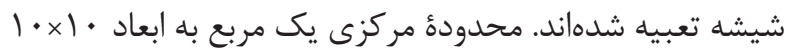

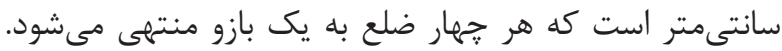

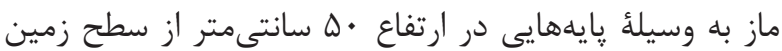

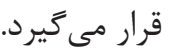

موشكا درون محدودهٔ مركزى و رو به يك يك بازوى باز قرار

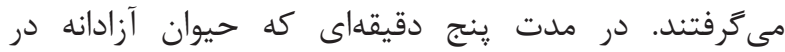

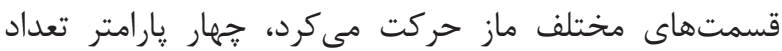

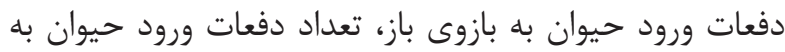

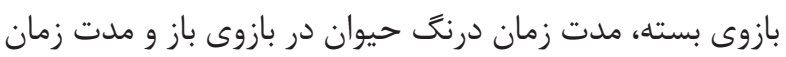

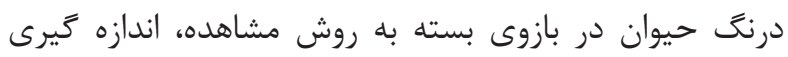

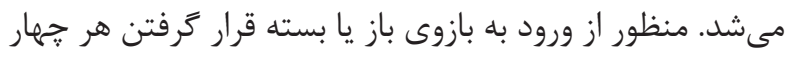

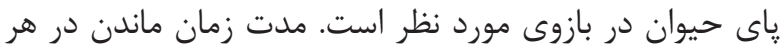
بازو نيز بر همين اساس محاسبه شده است.

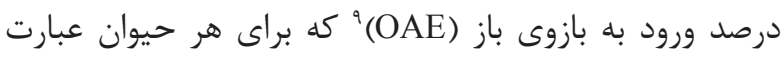

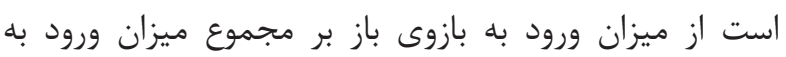

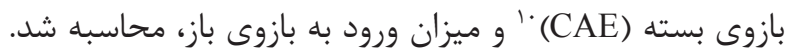

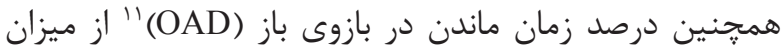

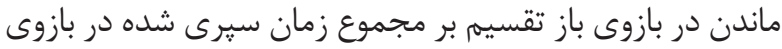

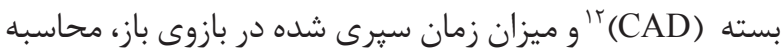

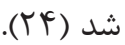

$0 \mathrm{AE} \%=\frac{O A E}{0 \mathrm{AE}+\mathrm{CAE}} \times 100 \quad 0 \mathrm{AD} \%=\frac{O A D}{0 \mathrm{AD}+\mathrm{CAD}} \times 100$

\footnotetext{
${ }^{11}$ Open arm duration

${ }^{12}$ Close arm duration

${ }^{13}$ Tukey
} 


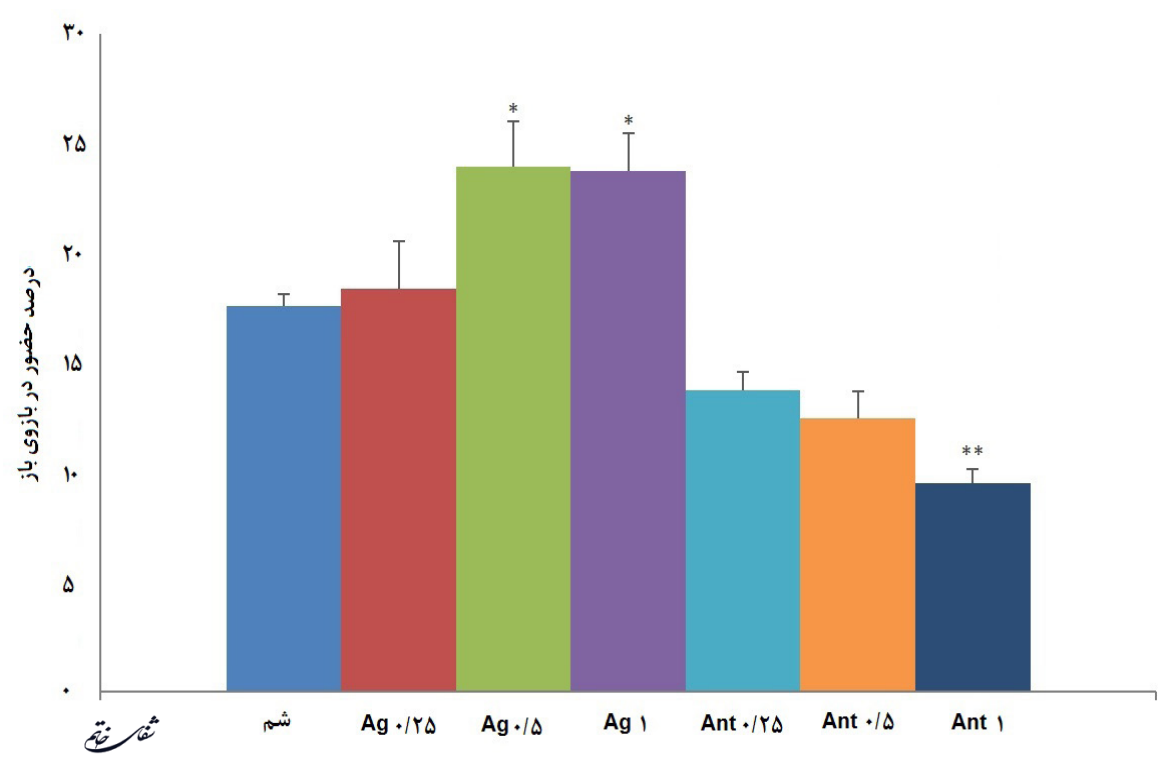

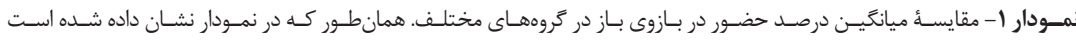

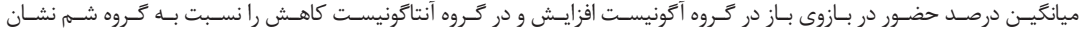

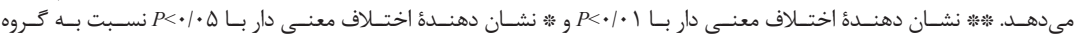

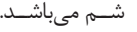

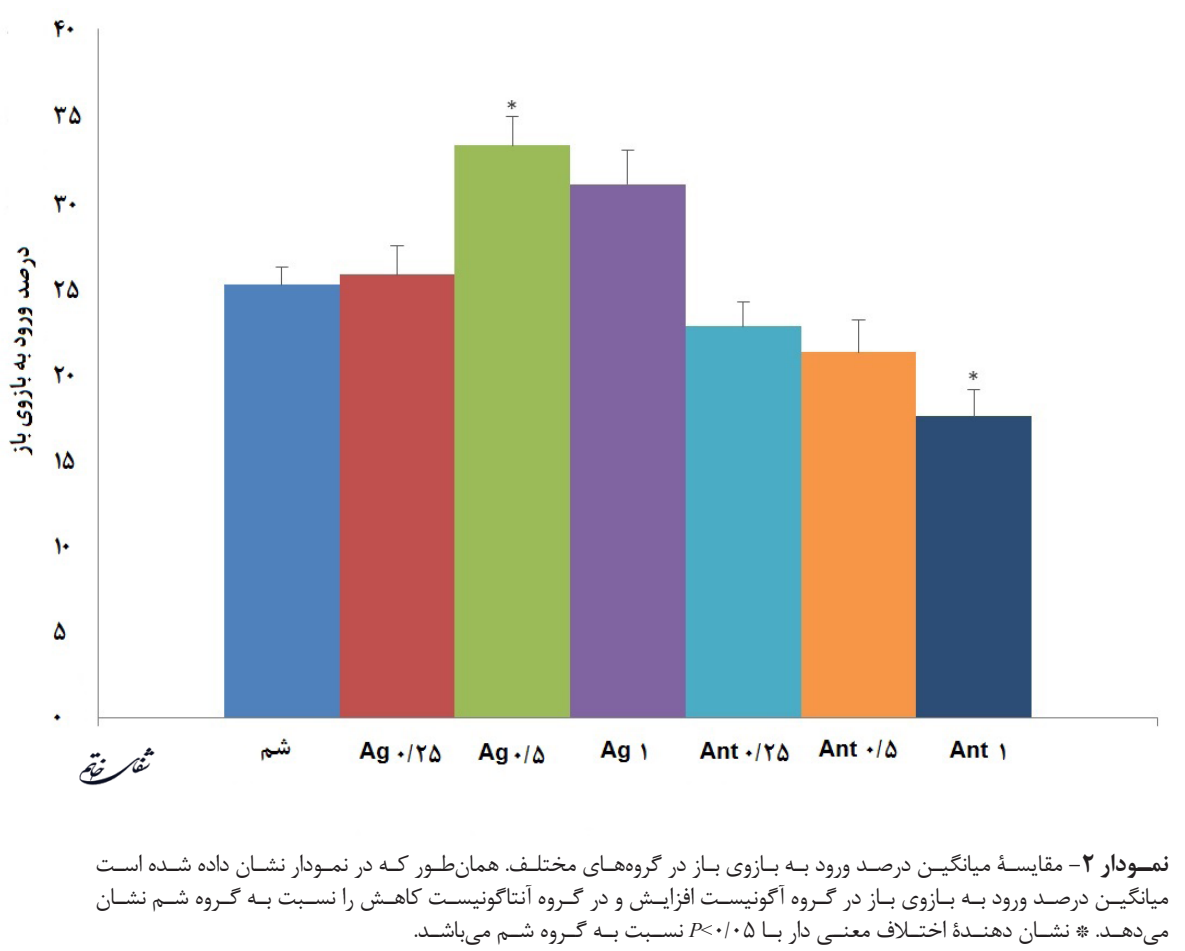

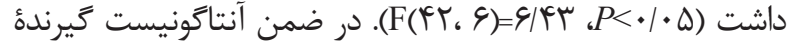

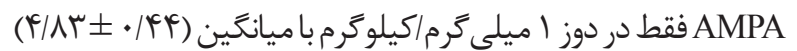

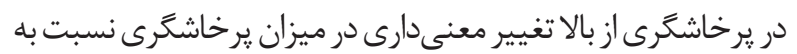

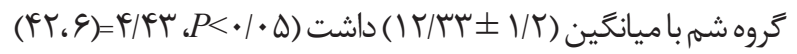

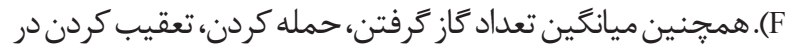

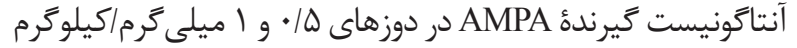

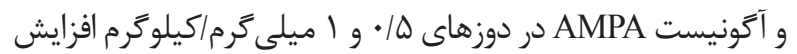

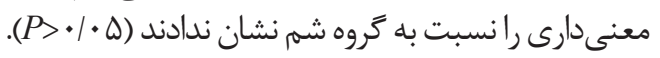

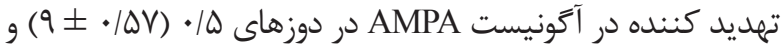

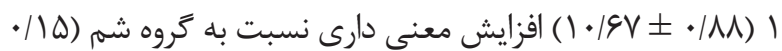
دوز

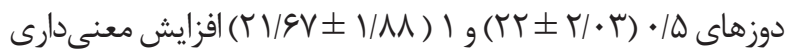

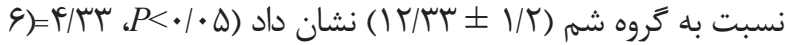
ميانگين.

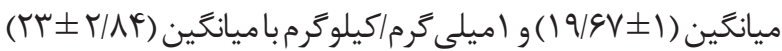

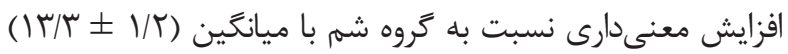



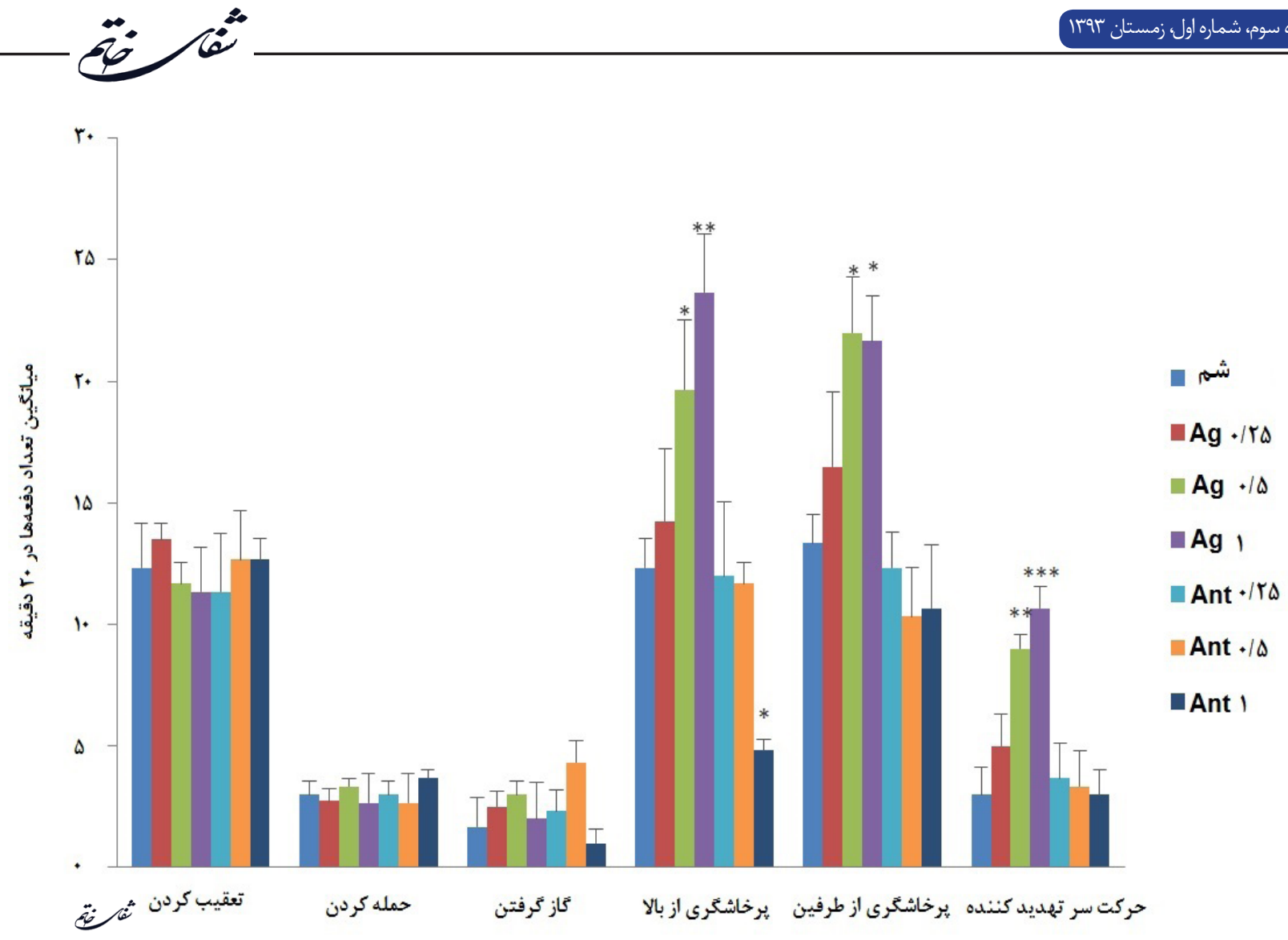

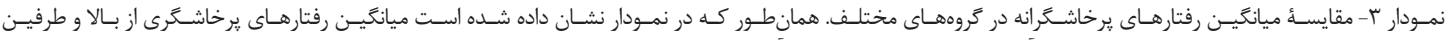

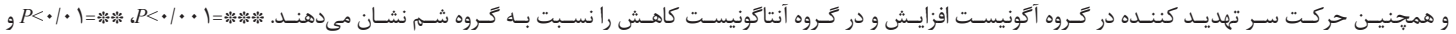

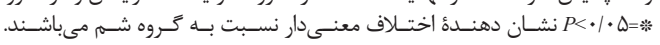

نقش تحريكى اين گيرنده مشخص گرديد. در مطالعات كذشته

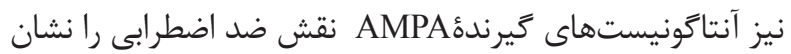

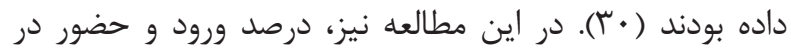

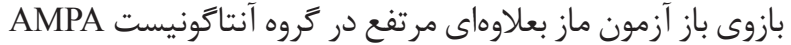

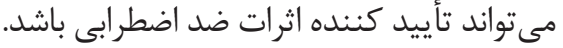

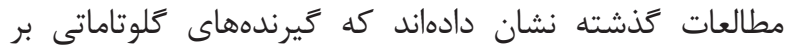

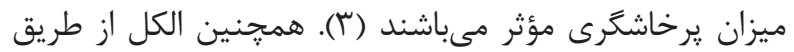

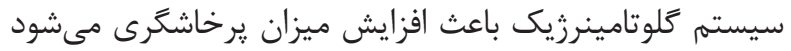

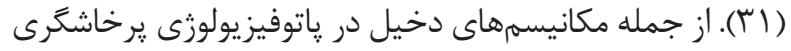

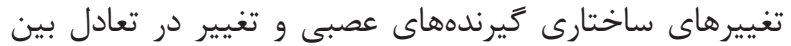

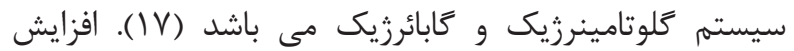

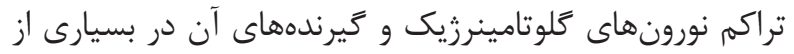

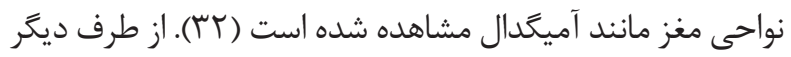

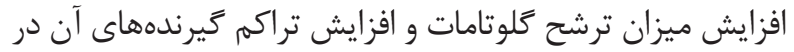

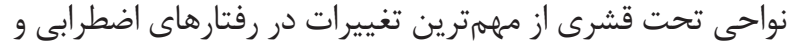

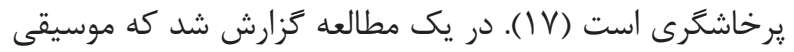

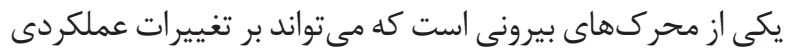

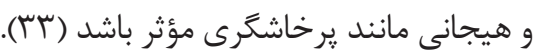

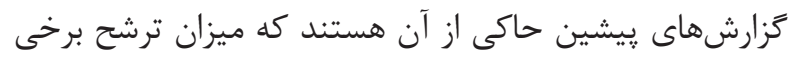

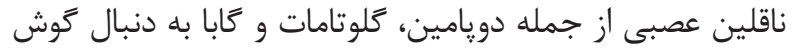
دادن به موسيقى دستخوش تغييرات مى كر دند. به طابه طور مثال، در
بحث و نتيجه كيرى

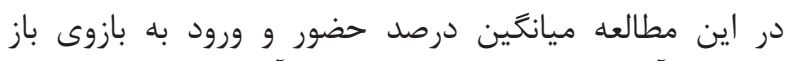

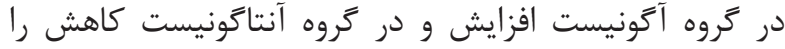

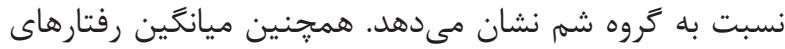

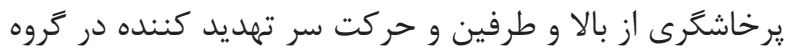

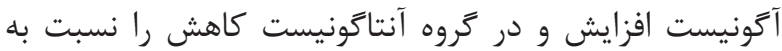

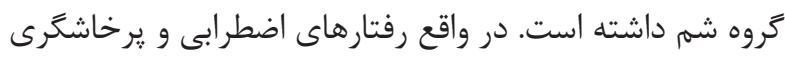

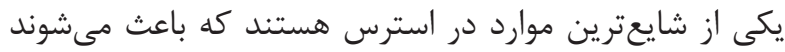

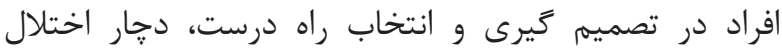

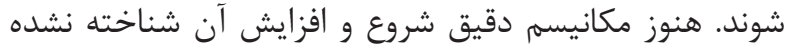

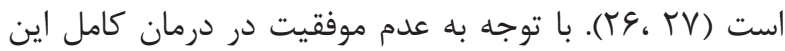

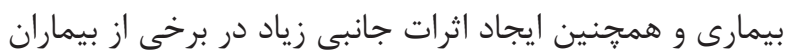

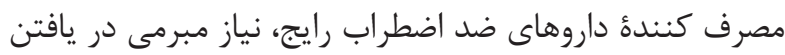

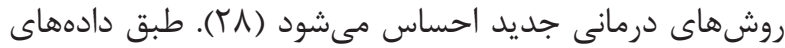

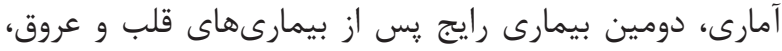

اختلال هاى روانى هستند (9 ب).

آميكدال به عنوان بخش اصلى در درك احساسات و ايجاد ياسخ

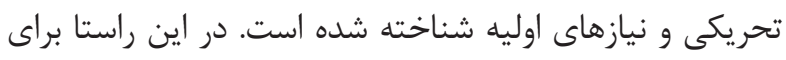

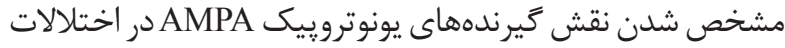

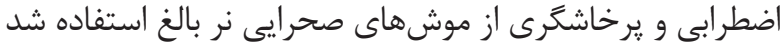

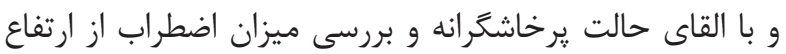


به نظر مىرسد اثرات مشاهده شده در اين مطالعه به دنبال

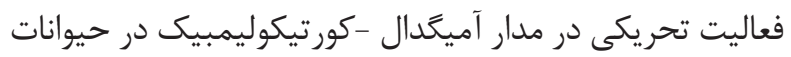

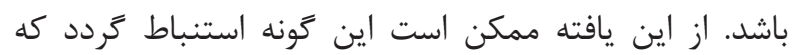

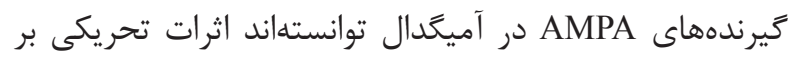

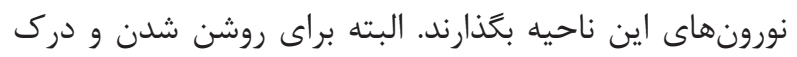

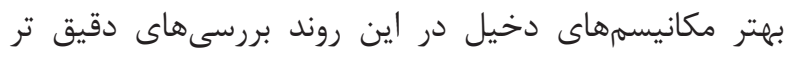
ضرورى به نظر مىرسد.

1. Siever L. Neurobiology of aggression and violence. Am J Psychiatry. 2008; 165(4): 429-42.

2. Owen C, Tarantello C, Jones M, Tennant C. Violence and aggression in psychiatric units. Psychiatr Serv. 1998; 49(11): 1452-7.

3. Miczek KA, de Almeida RM, Kravitz EA, Rissman EF, de Boer SF, Raine A. Neurobiology of escalated aggression and violence. Neurosci J. 2007; 27(44): 11803-6.

4. Hoptman MJ, D’Angelo D, Catalano D, Mauro CJ, Shehzad ZE, Kelly AC, et al. Amygdalofrontal functional disconnectivity and aggression in schizophrenia. Schizophr Bull. 2010; 36(5): 1020-8.

5. Goodwin FK, Jamison KR. Manic-depressive illness: bipolar disorders and recurrent depression. Oxford University Press. 2007.

6. Rapkin A. A review of treatment of premenstrual syndrome \& premenstrual dysphoric disorder. Psychoneuroendocrinology. 2003; 28: 39-53.

7. Kivisto AJ, Moore TM, Elkins SR, Rhatigan DL. The effects of PTSD symptomatology on laboratory-based aggression. J Trauma Stress. 2009; 22(4): 344-7.

8. George DT, Anderson P, Nutt D, Linnoila M. Aggressive thoughts and behavior: another symptom of panic disorder? Acta Psychiatr Scand. 1989; 79(5): 500-2.

9. Hale WW, Van Der Valk I, Engels R, Meeus W. Does perceived parental rejection make adolescents sad and mad? The association of perceived parental rejection with adolescent depression and aggression. J Adolesc Health. 2005; 36(6): 466-74.

10. Moore TM, Stuart GL, Meehan JC, Rhatigan DL, Hellmuth JC, Keen SM. Drug abuse and aggression between intimate partners: A meta-analytic review. Clin Psychol Rev. 2008; 28(2): 247-74.

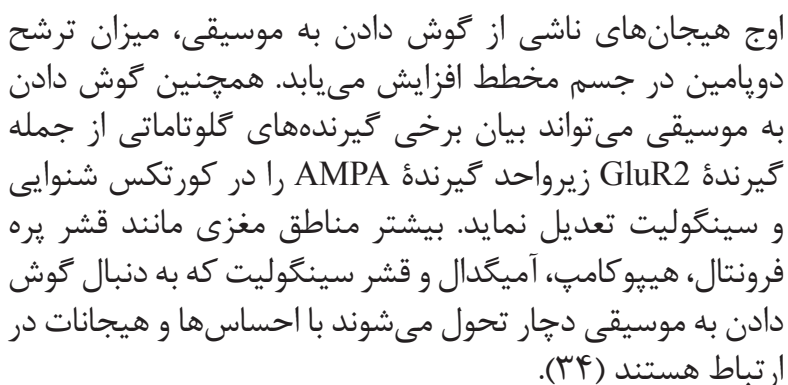

منابع

11. Le Doux JE. Emotion and the amygdala. In: Aggleton. 1992.

12. Swanson LW, Petrovich GD. What is the amygdala? Trends Neurosci. 1998; 21(8): 323-31.

13. Davis M, Shi C. The amygdala. Curr Biol. 2000; 10(4): R131.

14. Maren S. Neurotoxic basolateral amygdala lesions impair learning and memory but not the performance of conditional fear in rats. J Neurosci. 1999; 19(19): 8696703.

15. Neugebauer V, Li W, Bird GC, Han JS. The amygdala and persistent pain. Neuroscientist. 2004; 10(3): 221-34.

16. Taylor S. Anxiety sensitivity: Theory, research, and treatment of the fear of anxiety. $1^{\text {st }}$ ed. Routledge. 2014.

17. Feshbach S, Zagrodzka J. Aggression: Biological, developmental, and social perspectives. Springer Science \& Business Media. 2013.

18. Dingledine R, Borges K, Bowie D, Traynelis SF. The glutamate receptor ion channels. Pharmacol Rev. 1999; 51(1): 7-62.

19. Masu M, Tanabe Y, Tsuchida K, Shigemoto R, Nakanishi S. Sequence and expression of a metabotropic glutamate receptor. Nature. 1991; 349(6312): 760-5.

20. Solati J, Hajikhani R. Microinjection of NMDA receptor agents into the central nucleus of the amygdala alters water intake in rats. Iran J Basic Med Sci. 2010; 13(1): 53-8.

21. Solati J, Hajikhani R, Ahmadi M. Microinjection of NMDA Receptor Agents into the Central Nucleus of the Amygdale Alters Food Intake in Rats. J Appl Chem Res. $2010 ; 12: 53-8$.

22. Adamec RE, Burton P, Shallow T, Budgell J. NMDA receptors mediate lasting increases in anxiety-like 
behavior produced by the stress of predator exposureimplications for anxiety associated with posttraumatic stress disorder. Physiol Behav. 1998; 65(4): 723-37.

23. Paxinos G, Watson $\mathrm{C}$. The rat brain in stereotaxic coordinatesAcademic Press. New York. 1986: 55-60.

24. Lister RG. The use of a plus-maze to measure anxiety in the mouse. Psychopharmacol. 1987; 92(2): 180-5.

25. Miczek KA. A new test for aggression in rats without aversive stimulation: differential effects of d-amphetamine and cocaine. Psychopharmacol. 1979; 60(3): 253-9.

26. Hogben GL, Cornfield RB. Treatment of traumatic war neurosis with phenelzine. Arch Gen Psychiatry. 1981; 38(4): 440-5.

27. Strassman HD, Thaler MB, Schein EH. A prisoner of war syndrome: Apathy as a reaction to severe stress. Am J Psychiatry. 1956; 112(12): 998-1003.

28. Yap PM. Koro-a culture-bound depersonalization syndrome. Br J Psychiatry. 1965; 111(470): 43-50.
29. Tulchinsky TH, Varavikova EA, Bickford JD. The new public health. Academic Press. 2013.

30. Karcz-Kubicha M, Liljequist S. Evidence for an anxiogenic action of AMPA receptor antagonists in the plus-maze test. Eur J Pharmacol. 1995; 279(2): 171-7.

31. Newman EL, Chu A, Bahamón B, Takahashi A, DeBold JF, Miczek KA. NMDA receptor antagonism: escalation of aggressive behavior in alcohol-drinking mice. Psychopharmacol. 2012; 224(1): 167-77.

32. Tran L, Lasher B, Young K, Keele N. Depletion of serotonin in the basolateral amygdala elevates glutamate receptors and facilitates fear-potentiated startle. Transl Psychiatry. 2013; 3(9): e298. doi: 10.1038/tp.2013.66.

33. Ahmadi M, Banazadeh Dardashti M, Karimzadeh F. The Anti-aggressive Effect of Music Therapy in an Animal Model of Schizophrenia. Shefaye Khatam. 2014; 2(1): 51-5.

34. Salimpoor VN, Benovoy M, Larcher K, Dagher A, Zatorre RJ. Anatomically distinct dopamine release during anticipation and experience of peak emotion to music. Nat Neurosci. 2011; 14(2): 257-62. 